\title{
The Use of a Daily Quiz 'TOPday' as Supportive Learning Method for Medical Students
}

\author{
Martijn F. H. Maessen \\ Orthopaedic Research Laboratory, Department of Orthopaedics \\ Radboud Institute for Health Sciences, Radboud university medical center \\ Nijmegen, The Netherlands \\ $\&$ \\ Department of Physiology, Radboud Institute for Health Sciences \\ Radboud university medical center, Nijmegen, The Netherlands \\ E-mail: martijn.maessen@radboudumc.nl
}

Cornelia R. M. G. Fluit

Radboudumc Health Academy, Department for Research in Learning and Education

Radboud university medical center, Nijmegen, The Netherlands

E-mail: Lia.Fluit@radboudumc.nl

Micha Holla

Department of Orthopaedics, Radboud Institute for Health Sciences

Radboud university medical center, Nijmegen, The Netherlands

E-mail: Micha.Holla@radboudumc.nl

Gea Drost

Department of Neurology and Neurosurgery, University of Groningen

University Medical Center Groningen, Groningen, The Netherlands

E-mail: g.drost@umcg.nl 


\title{
Macrothink
}

Marc A. T. M. Vorstenbosch

Department of Anatomy, Radboud university medical center, Nijmegen, The Netherlands E-mail: Marc.Vorstenbosch@radboudumc.nl

\author{
Maarten C. de Waal Malefijt \\ Department of Orthopaedics, Radboud Institute for Health Sciences \\ Radboud university medical center, Nijmegen, The Netherlands \\ E-mail: Maarten.deWaalMalefijt@radboudumc.nl
}

Jan G. M. Kooloos

Department of Anatomy, Radboud university medical center, Nijmegen, The Netherlands E-mail: Jan.Kooloos@radboudumc.nl

Esther Tanck (Corresponding author)

Orthopaedic Research Laboratory, Department of Orthopaedics

Radboud Institute for Health Sciences, Radboud university medical center

P.O. Box 9101, 6500 HB Nijmegen, The Netherlands

E-mail: esther.tanck@radboudumc.nl

Received: August 1, 2016 Accepted: September 21, 2016 Published: October 2, 2016

doi:10.5296/jei.v2i2.9809 URL: http://dx.doi.org/10.5296/jei.v2i2.9809

\begin{abstract}
Medical students consider anatomy, neurology, and traumatology as difficult study topics. A recent study showed that the daily quiz 'Two Opportunities to Practice per day (TOPday)' positively supported biomedical students in analyzing and solving biomechanical problems. The main purpose of this study was to investigate the effect of TOPday on self-confidence, enthusiasm, and test results for the topics anatomy, neurology and traumatology. Second-year medical students were enrolled in a four-week course on the human skeletal system at the Radboudumc $(\mathrm{n}=799)$. They were randomized over three topic groups (anatomy, neurology, and traumatology) and received TOPday quizzes on every course day. At the end of the course students filled in a non-anonymous questionnaire. Students highly appreciated
\end{abstract}


TOPday (7.5 \pm 0.9 ) and this did not differ between groups (anatomy: 7.4 \pm 0.8 ; neurology: $7.4 \pm 1.1$; traumatology: $7.5 \pm 0.8 ; \mathrm{P}=0.68)$. Many students reported that TOPday increased their self-confidence (65\% of the students) and enthusiasm (69\% of the students) for their topic. However, test results of the students did not improve. A potential explanation for the latter result may relate to the different cognitive processes that are required to study anatomy, neurology, and traumatology compared to biomechanics. In conclusion, appreciation, self-confidence and enthusiasm were positively associated with TOPday, but test results were not.

Keywords: Daily quiz, Formative test, Feedback, Digital environment, Repeated learning

\section{Introduction}

High-quality patient care is only feasible if physicians have received high-quality teaching during both their undergraduate and their residential years (Leach, 2001; Leach \& Philibert, 2006). Due to a growing body of knowledge, the rapid development of information and communication technology, lifelong learning has become essential for future physicians. As deep approaches to learning are a key element of lifelong learners, the learning environment should stimulate this type of learning (Baeten, Dochy, \& Struyven, 2008). This means that students should be active participants in the process of learning and self-regulate their learning (Baeten et al., 2008). For this self-regulation, feedback on the performance is essential (van Dinther, Dochy, \& Segers, 2011). If feedback is constructive it can lead to an increasing self-efficacy that in return is related to better academic performance (Chemers, $\mathrm{Hu}$, \& Garcia, 2001).

A digital learning environment can contribute to this kind of learning environment, whereby students are actively involved in their own education (Lameris, Hoenderop, Bindels, \& Eijsvogels, 2015; Ruiz, Mintzer, \& Leipzig, 2006; Tanck, Hannink, van Kuppeveld, Bolhuis, $\&$ Kooloos, 2013). Within such a learning environment repeated testing like spaced education has been shown to be a valuable element (Karpicke \& Roediger, 2008; Kerfoot, DeWolf, Masser, Church, \& Federman, 2007; Roediger \& Karpicke, 2006). Spaced education combines two principle psychological research findings, i.e., temporal distribution of learning (spacing effect) and retrieval practice (testing effect) (Kerfoot, 2010; Larsen, Butler, \& Roediger, 2008; Pashler, Rohrer, Cepeda, \& Carpenter, 2007; Sisti, Glass, \& Shors, 2007).

A promising method to combine a digital environment and spaced education is described by Tanck et al. (2014), who developed 'Two Opportunities to Practice per Day' (TOPday). TOPday is a digital daily quiz about biomechanics with immediate feedback. TOPday motivated biomedical students to be actively involved with this topic and increased their enthusiasm as well as their self-confidence for biomechanics. In addition, their test results for biomechanics were significantly higher compared to students who did not use the TOPday (Tanck et al., 2013; Tanck et al., 2014).

Although TOPday may be an effective tool to support biomedical students' problem-driving education, TOPday has not been applied or investigated in other disciplines of the medical curriculum. At the Radboud university medical center, we offer medical students in their 
second year a four-week course about the human musculoskeletal system. This course contains many new concepts and complex terminologies regarding anatomy, neurology, and traumatology. As these topics are often considered difficult topics by students, we wanted to know whether TOPday could be applied in a knowledge driven environment and support the learning of students (Carley \& Driscoll, 2001; Pandey \& Zimitat, 2007; Schon, Hart, \& Fernandez, 2002; Zinchuk, Flanagan, Tubridy, Miller, \& McCullough, 2010).

Therefore, the main purpose of this study was to investigate the effect of 'Two Opportunities to Practice per day (TOPday)' on self-confidence, enthusiasm, and test results for the topics anatomy, neurology, and traumatology. We hypothesized that students who use TOPday will have higher study results, are more enthusiastic and feel more self-confident about the topics compared to students who do not use TOPday.

\section{Methods}

\subsection{Students}

This study was conducted in two cohorts (2012 and 2013) of second-year medical students ( $n$ =799) who were enrolled in a four-week course on the human musculoskeletal system at the Radboudumc in Nijmegen, The Netherlands. Students could voluntarily attend lectures and were asked to do self-study-assignments covering anatomy, neurology, and traumatology. After each self-study-assignment, students could attend an interactive lecture where difficulties from the assignment and other questions of the students were discussed with the lecturer. After the four-week course, the students had to do a written examination that included the topics anatomy, neurology, and traumatology.

\subsection{TOPday}

During the course, medical students were encouraged to frequently study the different topics of the human musculoskeletal system via self-study assignments. TOPday was developed to aid and stimulate students to repeatedly study the subject matter. Medical students were randomly divided over three topic groups (anatomy, neurology, and traumatology). During the first three weeks of the course, the students received one TOPday quiz per day (Monday-Friday) about their topic via e-mail. The TOPday quiz consisted of one-best-answer items with increasing difficulty over the course. The questions were written by expert anatomists, neurologists, and trauma surgeons involved in the course and required less than 10 minutes to answer. After answering the questions online, students received feedback immediately (Figure 1). The rationale for this approach was to increase the students' motivation for repetitive learning and to give them an opportunity for self-assessment. In total, 15 TOPday quizzes per topic were sent to the students. At the end of the course, students were invited to fill in a questionnaire after which they performed the final examination. The three topics accounted for $36 \%$ of the total test score, where traumatology accounted for $14 \%$ and anatomy and neurology for $11 \%$ each. 
Example: Question 14

The capitate bone is found within the distal row of carpal bones. What bone structure from the proximal row articulates with the capitate bone most prominently?

A. Triquetral bone
B. Pisiform bone
C. Lunate bone
D. Scaphoid bone

Motivation of the correct answer (C):

The lunate bone lies proximally from the capitate bone. The proximal end of the capitate bone has a convex shape, whereas the lunate bone has concave shape. The joint between both bone structures has a so called ball and socket joint. The capitate bone articulates also with the scaphoid bone, but the articulation is more prominent by the lunate bone.

Figure 1. Example of a TOPday question on Anatomy (translated from Dutch)

\subsection{Ethical Considerations}

A week before the course, students were informed about the procedures and purpose of TOPday via e-mail. During the introductory lecture, students were informed about the procedure. It was stressed that participation was voluntarily and that they could unsubscribe from TOPday at any time without any consequences. In addition, students were assured that completing the non-anonymous questionnaire would not affect or influence their study grades. Privacy and confidentiality were guaranteed and results of this study were only accessible for the researchers involved. The questionnaire was linked to a student number, which was subsequently linked to the results of the final examination. Ethical principles of the World Medical Association Declaration of Helsinki were taken into account and students gave written consent to use the data for research purposes.

\subsection{Outcome Measures and Statistical Analysis}

After the final TOPday question, students were asked to complete a non-anonymous 
questionnaire containing 15 items, focused on motivation, appreciation, and organization/ logistics of TOPday. Students could also provide comments about the organization and content of TOPday. The questionnaire was made by experts in the field of study evaluation questionnaires. The reliability of the questionnaire was evaluated via Cronbach's Alpha. Students who completed the questionnaire as well as the final examination were included in the data analysis. Students who exchanged and completed TOPday questions of other topics than their own were excluded from the primary data analysis.

The following parameters were used for the statistical analysis:

(1) Questionnaire outcomes:

a. TOPday participation rate; number of TOPday questions completed ( 0 to 5,6 to 10,11 to 15 questions). This was asked for all topics to check for any exchange of questions between students. The three answer options were further categorized into low (0 to 5 questions, group A) and high (6 to 15 questions, group B) participation.

b. Increase (yes/no) in enthusiasm and self-confidence for anatomy, neurology, or traumatology, due to TOPday.

c. The students' appreciation for TOPday (scale 1 [very bad] to 10 [excellent]).

d. Organization of TOPday (1 [bad], 2 [sufficient], or 3 [good]).

e. Content of TOPday quizzes (1 [irrelevant] or 2 [relevant]).

f. Quality of the feedback of TOPday quizzes (1 [unclear] or 2 [clear]).

(2) Grades examination:

a. Total test score for the final examination (scale 0-10).

b. Sub-scores for anatomy, neurology and traumatology (scale 0-10).

To determine whether TOPday quizzes were associated with an increase in test score per topic, the number of TOPday quizzes completed versus test results were analyzed using two-way ANOVA and Tukey post hoc tests with factors: 1) received topic; 2) participation rate (group A [low] or B [high]); and 3) interaction between received topic and participation rate. Self-confidence and enthusiasm were analyzed with descriptive statistics in the group of students who actively participated (B group). In the results, data is shown as mean and standard deviation (SD). Statistical significance was set at $P<0.05$.

\section{Results}

\subsection{Participation Rate and Student Population}

The questionnaire had a good reliability (Cronbach's alpha 0.88). After the exclusion of students that did not participate in the final examination or questionnaire $(n=197)$, or students that completed multiple TOPday quizzes from other topics $(n=226), 376$ students were included for the final statistical analyses. Of these 376 students, 72 (19\%) had a low participation rate in TOPday (group A) and 304 (81\%) had a high participation rate in 
TOPday (group B). The number of males $(31 \%)$ and females $(69 \%)$ as well as TOPday participation rate did not differ between the three topics $(\mathrm{P}=0.51$ and $\mathrm{P}=0.69$, respectively; Table 1).

Table 1. Characteristics and TOPday participation rate of 374 medical students categorized by topics anatomy, neurology, and traumatology

\begin{tabular}{|c|c|c|c|c|}
\hline Allocated Topic & Anatomy & Neurology & Traumatology & p-Value \\
\hline$n$ & $n 115$ & $n 137$ & $n 124$ & - \\
\hline Sex (males, n) & $31(27 \%)$ & $43(31 \%)$ & $42(34 \%)$ & 0.51 \\
\hline \multicolumn{5}{|l|}{ Participation Rate } \\
\hline Group A (0-5 questions) & $22(19 \%)$ & $29(21 \%)$ & $21(20 \%)$ & \multirow{2}{*}{0.69} \\
\hline Group B (6-15 questions) & $93(81 \%)$ & $108(79 \%)$ & $103(80 \%)$ & \\
\hline \multicolumn{5}{|l|}{ Appreciation of TOPday } \\
\hline Overall students' appreciation & $7.4 \pm 0.8$ & $7.4 \pm 1.1$ & $7.5 \pm 0.8$ & 0.68 \\
\hline Organization (good; n, \%) & $84 \%$ & $85 \%$ & $83 \%$ & 0.86 \\
\hline Content of TOPday (relevant; n, \%) & $87 \%$ & $77 \%$ & $85 \%$ & 0.11 \\
\hline Feedback of TOPday (clear; n, \%) & $85 \%$ & $87 \%$ & $94 \%$ & 0.10 \\
\hline
\end{tabular}

\subsection{Appreciation}

The students' appreciation of TOPday did not differ between the three topics (Table 1). Within each topic, students of group B appreciated TOPday significantly higher compared to students of group A (anatomy: A $6.8 \pm 0.9$ vs. B 7.5 \pm 0.8 ; neurology: A $6.9 \pm 1.5$ vs. B 7.6 \pm 0.9 ; traumatology: A $7.1 \pm 1.0$ vs. B 7.6 $\pm 0.8 ; \mathrm{P}<0.01$ ). The majority of the students were satisfied with the organization, content, and feedback of TOPday and this did not differ between the three topics (Table 1). In general, students commented that they liked TOPday, but found it disappointing that they received only one topic instead of all three. Another general remark of the students was that they appreciated the feedback provided after they answered the TOPday quiz.

\subsection{Self-Confidence and Enthusiasm}

The majority of the students $(n=244,65 \%)$ who actively participated in TOPday, perceived an increase in self-confidence for their topic because of TOPday. This did not significantly differ between the topics anatomy $(n=67,72 \%)$, neurology $(n=78,72 \%)$, and traumatology $(\mathrm{n}=81,79 \%)(\mathrm{P}=0.46)$. Likewise, the majority of the students $(\mathrm{n}=259,69 \%)$ who actively participated in TOPday indicated that their enthusiasm for their topic increased because of TOPday. This did not significantly differ between the topics anatomy ( $\mathrm{n}=73,78 \%$ ), neurology $(n=83,77 \%)$, and traumatology $(n=80,78 \%)(P=0.96)$. 


\subsection{Test Results}

Test results of the final examination did not differ between students who received TOPday quizzes on anatomy (7.0 \pm 0.9$)$, neurology (7.2 \pm 0.9$)$, or traumatology $(7.0 \pm 1.0), \mathrm{P}>0.05$. Within each topic, there were no significant differences in test results for the topics between group A and B (Figure $2 \mathrm{~A}$ ).

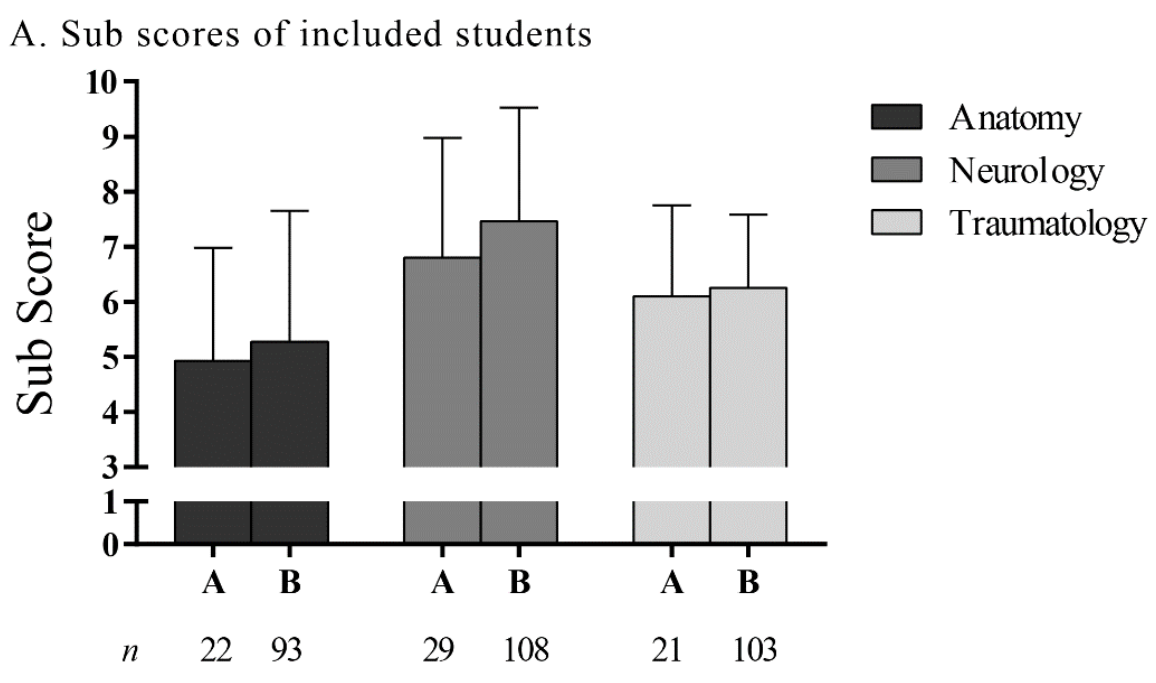

B. Sub scores of excluded students

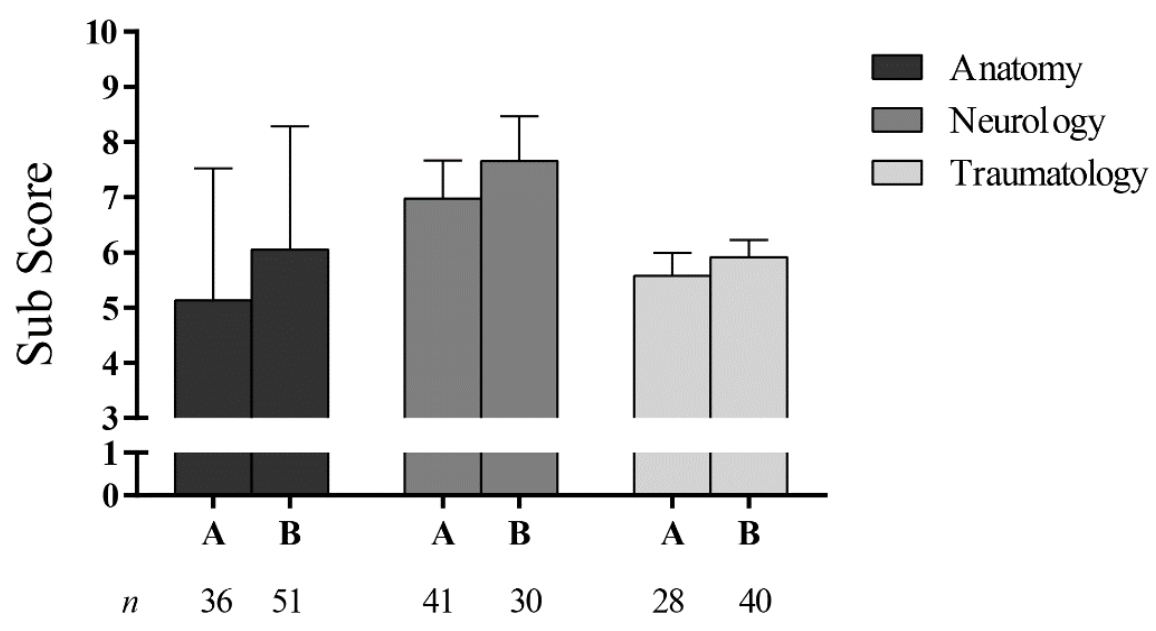

Figure 2. Sub score of the three topics (anatomy [black], neurology [dark grey], and traumatology [light grey]) grouped by the number of questions made (group A [0-5 questions], group B [6-15 questions]) for the A. included students and B. excluded students

Note. The sub score for anatomy, neurology, and traumatology did not differ between group A and $\mathrm{B}$ for either one of the topics. Data is presented as mean $\pm \mathrm{SD}$. 


\subsection{Sub Analysis: Excluded Students due to Multiple TOPday Topics}

Since we excluded a substantial number of students $(n=226)$ who completed multiple TOPday quizzes from other topics, we performed a sub analysis on this group. The majority of the excluded students appreciated TOPday, perceived an increase in self-confidence, and were enthusiastic for the topic (Table 2). Test results of the final examination did not differ between students who received TOPday quizzes on anatomy (7.0 \pm 0.9$)$, neurology (7.1 \pm 1.1 , or traumatology (7.1 \pm 0.8$), \mathrm{P}>0.05$. Within each topic, there were no significant differences in test results for the topics between group A and B (Figure 2 B). Students who made TOPday quizzes from multiple topics had higher test results for anatomy compared to students who made TOPday quizzes about one topic $(6.1 \pm 2.2$ vs. $5.3 \pm 2.4, \mathrm{P}=0.002)$, but lower test results for traumatology $(5.8 \pm 1.3$ vs. $6.3 \pm 1.3, \mathrm{P}=0.002)$. Neurology $(7.3 \pm 2.1$ vs. $7.6 \pm 2.1, \mathrm{P}=0.14)$ or total test score $(7.1 \pm 0.9$ vs. $7.1 \pm 0.9, \mathrm{P}=0.70)$ did not differ between students with multiple TOPday quizzes and students with one TOPday quiz, respectively.

Table 2. Characteristics, study results and TOPday participation rate of 226 medical students who were excluded due to the exchange of the topics anatomy, neurology, and traumatology

\begin{tabular}{|c|c|c|c|c|c|c|}
\hline Allocated Topic & Anatomy & Neurology & Traumatology & \multicolumn{3}{|c|}{ p-Value } \\
\hline$n$ & $n 87$ & $n 71$ & $n 68$ & \multicolumn{3}{|l|}{-} \\
\hline Sex (males, $n)$ & $35(40 \%)$ & $26(37 \%)$ & $25(37 \%)$ & \multicolumn{3}{|l|}{0.87} \\
\hline \multicolumn{7}{|l|}{ TOPday Participation Rate } \\
\hline Group A (0-5 questions) & $36(41 \%)$ & $41(58 \%)$ & $28(41 \%)$ & \multirow{2}{*}{\multicolumn{3}{|c|}{0.07}} \\
\hline Group B (6-15 questions) & $51(59 \%)$ & $30(42 \%)$ & $40(59 \%)$ & & & \\
\hline \multicolumn{4}{|l|}{ TOPday } & Topic & Group & Topic* Group \\
\hline \multicolumn{7}{|l|}{ Students' Appreciation } \\
\hline Group A & $7.6 \pm 1.2$ & $7.1 \pm 0.8$ & $7.5 \pm 0.7$ & \multirow{2}{*}{0.05} & \multirow{2}{*}{0.045} & \multirow{2}{*}{0.33} \\
\hline Group B & $7.8 \pm 1.0$ & $7.6 \pm 1.1$ & $7.5 \pm 0.9$ & & & \\
\hline Increase self-confidence (n, \%) & $41(80 \%)$ & $21(70 \%)$ & $31(78 \%)$ & - & 0.56 & - \\
\hline Increase enthusiasm (n, \%) & $40(78 \%)$ & $22(73 \%)$ & $32(80 \%)$ & - & 0.79 & - \\
\hline
\end{tabular}

\section{Discussion}

This study showed that the majority of the medical students who participated and completed the questionnaire highly appreciated TOPday and that they were motivated to be actively involved with the subject matter on a voluntary basis. Most students actively participated and reported that they appreciated this approach by email, including the feedback. Participation in TOPday did not require a lot of time and effort, indicating easy accessibility to participate. A substantial number of students perceived an increase in self-confidence and enthusiasm for the subject matter because of TOPday. In contrast, TOPday did not improve the test results.

Students indicated that they perceived TOPday quizzes as useful. This may relate to the 
voluntary aspect and immediate feedback after TOPday quizzes. The observed increase in enthusiasm and appreciation for (digital) study aids is in line with other studies (Evans, Zeun, \& Stanier, 2014; Palmen, Vorstenbosch, Tanck, \& Kooloos, 2015). The rationale for this approach was to increase the students' motivation for repetitive learning and to give them an opportunity for self-assessment, which fits in the recent changes of the medical curriculum at the Radboudumc. The recent changes place the student in the centre of their education by taking self-directed learning as starting-point. The students are responsible for their education and have to create a portfolio in which they reflect on their progression in medical education.

In the previous work of Tanck et al. (2014), a positive association was found between TOPday and test results for biomechanics. Despite the fact that students in the present study were stimulated to repeatedly study the subject matter, a higher participation rate for TOPday was not significantly associated with a higher final examination score. A potential explanation for this observation may relate to different cognitive processes required to study anatomy, neurology, and traumatology compared to biomechanics (Krathwohl, 2002). At the Radboudumc, learning anatomy, neurology, and traumatology, mainly requires remembering and understanding cognitive skills, whereas biomechanics requires higher cognitive skills, such as applying and analyzing concepts (Krathwohl, 2002). Possibly the effect of additional practice through TOPday is more rewarding when the topic is relatively complex or the obtained knowledge can be applied in different situations, like in biomechanics, whereas TOPday is less rewarding in case of retrieval practice of facts.

Previous studies indicated that the participation rate in formative quizzes was correlated to summative examination scores (Kibble, 2007; Palmen et al., 2015). The present study did not confirm this finding. Although students who completed TOPday quizzes from multiple topics performed better on anatomy, their test results for neurology or total test score did not differ compared to students who made TOPday quizzes for one topic. It should be noticed that it is rather difficult to find a causal relationship between TOPday and test results, since other competing learning activities (e.g., self-study assignments and lectures) were involved during the course as well (Roediger \& Karpicke, 2006). The number of TOPday questions could be increased in the future, resulting in better coverage of the subject matter which might improve the test results of the students (Kibble, 2007; Palmen et al., 2015). However, increasing the number of questions requires that the students have to spend more time on TOPday, which might discourage students to participate with quizzes (Logan, Thompson, \& Marshak, 2011; Palmen et al., 2015). Balancing the number of questions and time consumption for the students to complete the quiz is important. Students indicated they would have liked TOPday questions for all three of the topics. Some students therefore exchanged the different TOPday questions with each other. Although the students who did more than one topic were excluded from the analyses, there will remain uncertainty about the degree of honesty among students who filled in the questionnaire.

There are other possibilities to stimulate students to actively recall their knowledge or to search for additional information on the subject matter, such as blank exercises or supplementary questions as formative testing methods (Timby \& Smith, 2010). In addition, motivating students by providing them credit for the participation in quizzes, might also 
enhance the learning efficiency (Kibble, 2007). Alternatively, the TOPday questions of this study could be modified towards higher levels on the cognitive process dimension (Krathwohl, 2002). Then, our hypothesis that TOPday is more effective to improve test results when higher cognitive process skills are required could actually be tested. The questions at the final examination should then be changed towards higher cognitive levels as well (Crowe, Dirks, \& Wenderoth, 2008). Future research is warranted to determine whether TOPday is more effective to improve test results when higher cognitive process (e.g., applied) skills are required than when lower (e.g., memory) skills are required to answer the questions.

\subsection{Methodological Considerations}

This study is inherent to several limitations. First, we were unable to automatically track whether students exchanged TOPday quizzes between the different topics. To be able to take this into account, we asked the students whether they exchanged TOPday quizzes with each other. A second limitation is that we sent the TOPday quizzes via email so that TOPday quizzes were always available. Therefore, it is possible that some students saved TOPday quizzes until later in the course and made them just before the final examination.

\section{Conclusion}

Students highly appreciated TOPday and were motivated to be actively involved with the subject matter for anatomy, neurology, and traumatology. Students who participated actively in TOPday, perceived an increase in self-confidence and enthusiasm for the subject matter because of TOPday. However, we did not observe an increase in their test results compared to students who not actively participated in TOPday.

\section{References}

Baeten, M., Dochy, F., \& Struyven, K. (2008). Students' approaches to learning and assessment preferences in a portfolio-based learning environment. Instructional Science, 36(5-6), 359-374. http://dx.doi.org/10.1007/s11251-008-9060-y

Carley, S., \& Driscoll, P. (2001). Trauma education. Resuscitation, 48(1), 47-56. http://dx.doi.org/10.1016/s0300-9572(00)00317-8

Chemers, M. M., Hu, L., \& Garcia, B. F. (2001). Academic self-efficacy and first year college student performance and adjustment. Journal of Educational psychology, 93(1), 55-64. http://dx.doi.org/10.1037/0022-0663.93.1.55

Crowe, A., Dirks, C., \& Wenderoth, M. P. (2008). Biology in bloom: Implementing Bloom's Taxonomy to enhance student learning in biology. CBE Life Sci Educ, 7(4), 368-381. http://dx.doi.org/10.1187/cbe.08-05-0024

Evans, D. J., Zeun, P., \& Stanier, R. A. (2014). Motivating student learning using a formative assessment journey. J Anat, 224(3), 296-303. http://dx.doi.org/10.1111/joa.12117

Karpicke, J. D., \& Roediger, H. L. (3rd ed.). (2008). The critical importance of retrieval for learning. Science, 319(5865), 966-968. http://dx.doi.org/10.1126/science.1152408 
Kerfoot, B. P. (2010). Adaptive spaced education improves learning efficiency: A randomized controlled trial. J Urol, 183(2), 678-681. http://dx.doi.org/10.1016/j.juro.2009.10.005

Kerfoot, B. P., DeWolf, W. C., Masser, B. A., Church, P. A., \& Federman, D. D. (2007). Spaced education improves the retention of clinical knowledge by medical students: A randomised controlled trial. Med Educ, 41(1), 23-31. http://dx.doi.org/10.1111/j.1365-2929. 2006.02644.x

Kibble, J. (2007). Use of unsupervised online quizzes as formative assessment in a medical physiology course: Effects of incentives on student participation and performance. $A d v$ Physiol Educ, 31(3), 253-260. http://dx.doi.org/10.1152/advan.00027.2007

Krathwohl, D. R. (2002). A revision of bloom's taxonomy: An overview. Theory Into Practice, 41(4), 212-218. http://dx.doi.org/10.1207/s15430421tip4104_2

Lameris, A. L., Hoenderop, J. G., Bindels, R. J., \& Eijsvogels, T. M. (2015). The impact of formative testing on study behaviour and study performance of (bio)medical students: A smartphone application intervention study. BMC Med Educ, 15, 72. http://dx.doi.org/10.1186/ s12909-015-0351-0

Larsen, D. P., Butler, A. C., \& Roediger, H. L. (2008). Test-enhanced learning in medical education. Med Educ, 42(10), 959-966. http://dx.doi.org/10.1111/j.1365-2923.2008.03124.x

Leach, D. C. (2001). Changing education to improve patient care. Qual Health Care, 10(Suppl. 2), ii54-58. http://dx.doi.org/10.1136/qhc.0100054

Leach, D. C., \& Philibert, I. (2006). High-quality learning for high-quality health care: Getting it right. Jama, 296(9), 1132-1134. http://dx.doi.org/10.1001/jama.296.9.1132

Logan, J. M., Thompson, A. J., \& Marshak, D. W. (2011). Testing to enhance retention in human anatomy. Anat Sci Educ, 4(5), 243-248. http://dx.doi.org/10.1002/ase.250

Palmen, L. N., Vorstenbosch, M. A., Tanck, E., \& Kooloos, J. G. (2015). What is more effective: A daily or a weekly formative test? Perspect Med Educ, 4(2), 73-78. http://dx.doi.org/10.1007/s40037-015-0178-8

Pandey, P., \& Zimitat, C. (2007). Medical students' learning of anatomy: Memorisation, understanding and visualisation. Med Educ, 4l(1), 7-14. http://dx.doi.org/10.1111/j.13652929.2006.02643.x

Pashler, H., Rohrer, D., Cepeda, N. J., \& Carpenter, S. K. (2007). Enhancing learning and retarding forgetting: Choices and consequences. Psychon Bull Rev, 14(2), 187-193. http://dx.doi.org/10.3758/BF03194050

Roediger, H. L., \& Karpicke, J. D. (2006). Test-enhanced learning: Taking memory tests improves long-term retention. Psychol Sci, 17(3), 249-255. http://dx.doi.org/10.1111/j.14679280.2006.01693.x

Ruiz, J. G., Mintzer, M. J., \& Leipzig, R. M. (2006). The impact of E-learning in medical education. Acad Med, 81(3), 207-212. http://dx.doi.org/10.1097/00001888-200603000-00002 


\section{Macrothink}

Schon, F., Hart, P., \& Fernandez, C. (2002). Is clinical neurology really so difficult? J Neurol Neurosurg Psychiatry, 72(5), 557-559. http://dx.doi.org/10.1136/jnnp.72.5.557

Sisti, H. M., Glass, A. L., \& Shors, T. J. (2007). Neurogenesis and the spacing effect: Learning over time enhances memory and the survival of new neurons. Learn Mem, 14(5), 368-375. http://dx.doi.org/10.1101/1m.488707

Tanck, E., Hannink, G., van Kuppeveld, S. M., Bolhuis, S., \& Kooloos, J. G. (2013). The use of daily questions for educational purposes: A TOPday for students. Perspect Med Educ, 2(3), 162-164. http://dx.doi.org/10.1007/s40037-013-0052-5

Tanck, E., Maessen, M. F., Hannink, G., van Kuppeveld, S. M., Bolhuis, S., \& Kooloos, J. G. (2014). The effect of a daily quiz (TOPday) on self-confidence, enthusiasm, and test results for biomechanics. Perspect Med Educ, 3(1), 4-14. http://dx.doi.org/10.1007/s40037-0130096-6

Timby, B. K., \& Smith, N. E. (2010). Introductory medical-surgical nursing (10th ed.). Philadelphia: Wolters Kluwer Health/Lippincott Williams \& Wilkins.

van Dinther, M., Dochy, F., \& Segers, M. (2011). Factors affecting students' self-efficacy in higher education. Educational Research Review, 6(2), 95-108. http://dx.doi.org/10.1016/ j.edurev.2010.10.003

Zinchuk, A. V., Flanagan, E. P., Tubridy, N. J., Miller, W. A., \& McCullough, L. D. (2010). Attitudes of US medical trainees towards neurology education: "Neurophobia"-A global issue. BMC Med Educ, 10, 49. http://dx.doi.org/10.1186/1472-6920-10-49

\section{Copyright Disclaimer}

Copyright for this article is retained by the author(s), with first publication rights granted to the journal.

This is an open-access article distributed under the terms and conditions of the Creative Commons Attribution license (http://creativecommons.org/licenses/by/3.0/). 